Published in final edited form as:

Gastroenterology. 2013 June ; 144(6): 1252-1261. doi:10.1053/j.gastro.2013.01.068.

\title{
The Epidemiology of Pancreatitis and Pancreatic Cancer
}

\author{
Dhiraj Yadav ${ }^{1}$ and Albert B. Lowenfels ${ }^{2}$ \\ ${ }^{1}$ University of Pittsburgh Medical Center, Pittsburgh, PA \\ ${ }^{2}$ New York Medical College, Valhalla, NY
}

\section{Abstract}

Acute pancreatitis is one of the most frequent gastrointestinal causes for hospital admission in the US. Chronic pancreatitis, although lower in incidence, significantly reduces patients' quality of life. Pancreatic cancer has high mortality and is 1 of the top 5 causes of death from cancer. The burden of pancreatic disorders is expected to increase over time. The risk and etiology of pancreatitis differ with age and sex, and all pancreatic disorders affect Blacks more than any other race. Gallstones are the most common cause of acute pancreatitis, and early cholecystectomy eliminates the risk of future attacks. Alcohol continues to be the single most important risk factor for chronic pancreatitis. Smoking is an independent risk factor for acute and chronic pancreatitis, and its effects could synergize with those of alcohol. Significant risk factors for pancreatic cancer include smoking and non-O blood groups. Alcohol abstinence and smoking cessation can alter progression of pancreatitis and reduce recurrence; smoking cessation is the most effective strategy to reduce the risk of pancreatic cancer.

\section{Keywords \\ pancreatitis; cancer; epidemiology}

\section{Introduction}

Acute pancreatitis (AP) caused approximately 275,000 hospitalizations in $2009^{1}$ (an increase of more than 2-fold since $1988^{2}$ ) and is the single most frequent gastrointestinal cause of hospital admissions in the US. Although chronic pancreatitis (CP) is lower in incidence and prevalence than AP, CP significantly affects patients' quality of life; it is characterized by chronic abdominal pain, frequent disease exacerbations, and exocrine and/or endocrine insufficiency. Pancreatic cancer has a lower incidence than many other types of cancer, but is the fourth most common cause of death from cancer. We review the epidemiology and risk factors for pancreatitis and pancreatic cancer.

\footnotetext{
(C) 2013 The American Gastroenterological Association. Published by Elsevier Inc. All rights reserved.

Correspondence: Dhiraj Yadav, MD MPH, Associate Professor, Division of Gastroenterology \& Hepatology, University of Pittsburgh Medical Center, 200 Lothrop Street, M2, C-wing, Pittsburgh, PA 15213, Tel: 412648 9825, Fax: 4123838992 yadavd@ upmc.edu.

Conflict of Interest: None

Views presented in this article belong solely to the authors.

Publisher's Disclaimer: This is a PDF file of an unedited manuscript that has been accepted for publication. As a service to our customers we are providing this early version of the manuscript. The manuscript will undergo copyediting, typesetting, and review of the resulting proof before it is published in its final citable form. Please note that during the production process errors may be discovered which could affect the content, and all legal disclaimers that apply to the journal pertain.
} 


\section{Descriptive Epidemiology \\ Incidence, Prevalence, and Trends}

The annual incidence of $\mathrm{AP}^{3-5}$ ranges from 13 to $45 / 100,000$ persons, and $\mathrm{CP}^{5,6}$ from 5 to $12 / 100,000$; the prevalence of CP is about 50/100,000 persons ${ }^{6,7}$. The incidence of pancreatitis and pancreatic cancer in the US are shown in Figure $1^{7-9}$. Population distributions are mostly reported from the US, Europe, and Japan, but data are emerging from other regions ${ }^{4}$. Variations in disease estimates result from differences in study methodology, difficulties in establishing accurate diagnoses, the use of different diagnostic criteria, and local lifestyle risk factors ${ }^{10}$. Further, analyses that use administrative data or include non-unique patients can increase estimates. There are also regional differences in demographic distributions: alcohol-related pancreatitis is more common in the West and Japan, compared with other Asian countries, and there is wide variation in the prevalence of a form of CP that is endemic to tropical countries (20-125/100,000 persons reported in 2 parts of South India) ${ }^{11,12}$.

A large increase in the incidence of AP and a smaller increase in the incidence of $\mathrm{CP}$ have been reported in population studies $6,7,10$. The increasing incidence of obesity is likely to contribute to that of AP, because obesity promotes gallstone formation-the most common cause of AP. Another major contributor is increased availability and use of tests to measure serum levels of pancreatic enzymes, which detect milder cases of AP but can also result in over diagnosis ${ }^{13}$. In the US, emergency room use of tests to measure serum pancreatic enzymes reportedly increased by more than $60 \%$ over a 10 -year period ${ }^{14}$.

Increases in the prevalence of $\mathrm{CP}$ could result from greater availability of high-quality crosssectional imaging techniques that can detect morphologic changes in the pancreas. Alcohol consumption has been increasing in the developing countries, such as China and India, ${ }^{15}$ due to rapid urbanization and increased affluence. This increase would be expected to increase the burden of alcohol-related pancreatitis in these countries. In contrast, alcohol consumption has been generally stable or decreased in many North American and European countries.

The global annual incidence rate for pancreas cancer is about $8 / 100,000$ persons ${ }^{16}$. Adenocarcinoma is the most frequent type of pancreatic cancer; slower-growing endocrine tumors account for only a small fraction of the total burden of disease. As for nearly all cancers, incidence rates of pancreatic cancer vary among countries, with approximate 5- to 7 -fold differences between countries with the lowest and highest incidence; rates reported from African countries are low because of insufficient data. There has been a concerted search for environmental factors that might account for this variation. In addition to countryspecific differences, subtle geographic and regional differences exist, with countries located on or close to the equator having lower rates than antipodal countries. In 2008, there were an estimated 279,000 new diagnoses of pancreatic cancer worldwide, accounting for $2.2 \%$ of all new cases of cancer ${ }^{17}$.

\section{Age and Sex}

Although equal proportions of men and women develop AP, CP is more common among men. The risk of AP progressively increases with age, whereas CP mainly affects middleaged individuals. Age and sex distribution differ based on etiology (see Figures 2 and 3). Alcohol-related pancreatitis is more common in men, though sex differences disappear with similar levels of alcohol consumption ${ }^{18}$. Studies are needed to determine whether genetic factors increase risk in men. Pancreatitis in women is more likely related to gallstones, endoscopic retrograde cholangiopancreatography, or autoimmune diseases, or to be 
idiopathic. Variations in age and sex distribution among geographic regions likely arise from differences in etiology 19 . Although pancreatitis is uncommon among persons younger than 20 years old, it is increasingly recognized in the pediatric population ${ }^{20}$. Common etiologies of AP in pediatric patients include gallstones, medication, and idiopathic disease ${ }^{21}$. Genetic factors are likely to contribute to unexplained recurrent $\mathrm{AP}$ or $\mathrm{CP}^{22,23}$.

As for other cancers, fewer than $10 \%$ of cases of pancreatic cancer occur among individuals younger than 55 years old, and the median age of onset is 71 years. Figure 4 compares US rates of pancreatic cancer by sex, race, and ethnicity. In all groups, men have higher incidence rates than women.

\section{Race}

The risk of pancreatitis is 2-3 fold higher among Blacks than Whites ${ }^{2,24}$, and pancreatic cancer rates are considerably higher in Blacks than in any other racial group ${ }^{9}$, a disparity similar to that of lung cancer. Little is known about the reasons for the racial disparityfurther research is urgently needed. Distributions of lifestyle factors, such as heavy drinking or smoking, are similar among US Blacks and Whites ${ }^{25}$. Studies are needed to determine whether the observed differences result from dietary, genetic, or other factors.

\section{Lifestyle Factors}

\section{Alcohol}

Although patients who have never consumed alcohol can develop pancreatitis, alcohol appears to increase the sensitivity of the pancreas to injury from other factors (genetic or environmental), ${ }^{26}$ and the risk of pancreatitis is undoubtedly increased by alcohol consumption. The prevalence of pancreatitis is increased approximately 4-fold among subjects with a history of alcoholism, compared to those without ${ }^{27}$. The absolute risk of pancreatitis from alcohol consumption is much lower than that for chronic liver disease or cirrhosis, and ranges from $2 \%$ to $5 \%$ among patients who consume large amounts of alcohol ${ }^{18,27,28}$. Alcohol use is the single most common cause of $\mathrm{CP}^{29,30}$ (its attributable risk is about $40 \%$ ), and after gallstones, is the second-most common cause of $\mathrm{AP}^{10}$.

Alcohol was shown to increase the risk of pancreatitis in a dose-dependent manner in a recent cohort study ${ }^{28}$. The risk for $\mathrm{CP}$ increases at threshold of approximately 5 drinks/day (an odds ratio of 3.1) ${ }^{31}$, based on a large case-control study, or at 4 drinks/day, based on a meta-analysis of published literature (a relative risk of 2.5$)^{32}$. These data indicate a clear increase in risk among heavy drinkers, though lower levels of alcohol consumption might not be completely safe-especially among subjects who have had an episode of AP or are diagnosed with $\mathrm{CP}$.

After patients had a first episode of alcohol-related AP, their risk of progression to CP was found to be approximately $14 \%$ with complete abstinence or only occasional drinking, $23 \%$ with decreased but daily drinking, and $41 \%$ with drinking at the same levels as before the $\mathrm{AP}$ attack ${ }^{33}$. A randomized controlled trial reported that the risk of recurrence after a first episode of acute alcohol-related AP decreased significantly following repeated counseling against alcohol consumption ${ }^{34}$.

Two cohort studies have examined the relationship between pancreatitis and consumption of different types of alcohol ${ }^{28,35}$. A Danish study associated pancreatitis with consumption of $>14$ beers/week, but not wine or spirits ${ }^{28}$. A Swedish study associated AP with 5 or more drinks of spirits on a single occasion, but not with beer or wine ${ }^{35}$. One limitation of these analyses was the small numbers of subjects in the heavy-drinking groups, who have the greatest risk of developing pancreatitis. Pancreatitis is observed in all populations, 
irrespective of the type of beverage they consume, but the contribution of beverage type to risk requires further study.

With regard to binge drinking, a study compared the number and frequency of hospital admission of patients with AP during the Munich Oktoberfest with 2 other time periods and found no significant increase during this 16-day period of increased beer drinking ${ }^{36}$. In this study, a brief period of increased drinking (above baseline low levels) did not appear to increase the risk of AP, at a population level. The risk seems to be higher in patients with a prior history of heavy drinking, many of whom report an increase in alcohol consumption during the weeks preceding their attack. An interesting study from Netherlands found that about 50\% patients with alcohol-related AP developed symptoms 2 days after they stopped drinking, ${ }^{37}$ raising questions about whether the amount, duration, and/or withdrawal of binge drinking affects risk for AP.

It is difficult to implicate alcohol as an independent risk factor for pancreatic cancer because of the close association between alcohol and smoking - a proven risk factor for pancreatic cancer. If alcohol affects pathogenesis of pancreatitis, it could promote the effects of other risk factors, such as smoking. Recent studies concluded that heavy drinkers might have an increased risk of pancreatic cancer. Gapstur et al., in a study of non-smokers, observed an increased risk of pancreatic cancer only among persons who consumed more than 3 drinks per day ${ }^{38}$. Examining 10 case-control studies, Lucenteforte et al. found an increased risk of pancreatic cancer among persons who consumed more than 9 drinks per day ${ }^{39}$.

\section{Smoking}

Since 1982 , when smoking was initially reported as a risk factor for $\mathrm{CP}^{40}$, numerous studies have confirmed this association. Smoking and alcohol are co-factors that increase the risk of pancreatitis. In a multi-center study, ever and current smoking was reported by $71.4 \%$ and $47.3 \%$ of patients with $\mathrm{CP}$, respectively, at the time of enrollment. Drinking and smoking habits often co-exist, and the prevalence of smoking was found to increase with the amount of alcohol consumed ${ }^{31}$.

A meta-analysis of 12 studies of approximately 1500 patients with CP associated levels of smoking with CP. The excess risk for $\mathrm{CP}$ was more than 2-fold (a relative risk of 2.4) among subjects who smoked less than 1 pack/day and more than 3-fold (a relative risk of 3.3) among those who smoked 1 or more packs/day. The risk was higher for current smokers (a relative risk of 2.5) and significantly lower among former smokers (a relative risk of 1.4) ${ }^{41}$. Although smoking increases the risk of $\mathrm{CP}$ independently of alcohol, the effects of smoking are stronger for alcohol-related CP.

Smoking also increases the risk for $\mathrm{AP}^{42-44}$. A Swedish study ${ }^{43}$ found that smoking increased the risk for non-gallstone-related (by about 2-fold), but not gallstone-related $\mathrm{AP}^{43}$. The risk was especially high in patients who consumed alcohol (defined as $\geq 400$ grams/ month), current smokers, and those with $\geq 20$ pack years of smoking. The risk was highest in subjects who had all these characteristics (a relative risk of 4.12); these patients had to stop smoking for 2 decades to reduce their risk level to that of never-smokers.

Smoking has been calculated to attribute $25 \%$ of the risk for $\mathrm{CP}$, and continued smoking after a diagnosis accelerates disease progression ${ }^{45}$. Physicians often focus on counseling patients with CP against alcohol consumption and underestimate the role of smoking ${ }^{46}$, thereby missing opportunities to counsel patients on smoking cessation or to refer them to behavior modification programs. 
The relationship between smoking and pancreatic cancer has been studied extensively; there are nearly 500 references listed in PubMed on this association. Studies have consistently confirmed the relationship between smoking and pancreatic cancer, with smokers having about a 2-fold excess risk compared with non-smokers. This increase in risk is smaller than for lung cancer, but is similar that of other tumors, such as bladder cancer. This could be because the bladder and pancreas each have indirect exposure to tobacco carcinogens.

A recent pooled analysis of 12 case-control studies that included nearly 13,000 patients with pancreatic cancer concluded that current smokers had an odds ratio of 2.2, compared with never smokers ${ }^{47}$. As expected, risk increased in proportion to smoking. For ex-smokers, the odds ratio was 1.2 . With smoking cessation, risk gradually decreases, but 10-20 years are required before the smoking-related risk disappears.

The association between exposure to environmental tobacco smoke and the subsequent risk of pancreatic cancer is controversial. Two studies of the same European cohort reported an excess risk of pancreatic but no other cancers after childhood exposure to tobacco smoke. Surprisingly, the risks were as high or higher than expected from direct smoking, so the findings could result from chance or an undetected bias ${ }^{48,49}$.

If smoking doubles the risk of pancreatic cancer, and if approximately $30 \%$ of the population smokes, then about $25 \%$ of all cases of pancreatic cancer can be attributed to smoking. This makes smoking cessation the single most effective strategy to reduce the burden of pancreatic cancer.

Why is smoking such a strong risk factor for pancreatic cancer? Tobacco smoking releases many carcinogens. Several gene products mediate the degradation of tobacco carcinogens; a recent study examined several detoxifying genes in 455 patients with pancreatic cancer ${ }^{50}$. Variants in genes such as CYP1B1-4390-GG and uridine $5^{\prime}$ -

diphosphoglucuronosyltransferase reduced the risk of pancreatic cancer, whereas variants in others, such as GSTM1, increased risk. Little is known about the mechanisms by which these genes affect cancer risk, but their products could affect the inflammatory response, fibrosis, cell proliferation, and other processes involved in carcinogenesis 51 .

\section{Diet}

Over the course of an entire lifetime, each individual consumes several thousand pounds of food; given such exposure, it seems reasonable that diet would affect risk for different digestive diseases and cancer, including those of the pancreas. However, it has been a challenge to establish a link between diet and cancer, and case-control studies (the most common type of epidemiologic studies) are prone to recall bias. Cohort studies in which dietary information is collected before subjects develop cancer are more reliable, but have not provided consistent evidence for an association.

A Mediterranean dietary pattern, when combined with other factors indicative of a healthy lifestyle, protects against pancreatic cancer ${ }^{52}$. Red meats, particularly when cooked at high temperatures, increase the risk of pancreatic cancer ${ }^{53}$. Based on data from more than 500,000 persons in 10 countries, consumption of fruit and vegetables does not decrease the risk for pancreatic cancer ${ }^{54}$. Similarly, carbohydrate intake was not associated with pancreatic cancer risk ${ }^{55}$. The role of dietary factors in the etiology of pancreatitis is unclear. This is an important area for future research — especially with growing evidence for the roles of the intestinal microbiota in health and disease ${ }^{56}$. 


\section{Obesity}

In a population-based study, abdominal adiposity, but not total adiposity or body mass index (BMI), increased the risk for AP, after controlling for demographic and lifestyle factors ${ }^{57}$. The effect was similar for gallstone- and non-gallstone-related AP and for mild and severe AP. Individuals with a waist circumference of $>105 \mathrm{~cm}$ had a 2-fold increase in risk of AP (a relative risk of 2.37), compared with those with a waist circumference of $75-85 \mathrm{~cm}$. Obesity also increases the severity of AP. In a recent meta-analysis, compared with subjects who had a normal BMI, obese subjects (BMI $>30 \mathrm{~kg} / \mathrm{m}^{2}$ ) had a higher risk of AP (summary relative risk of 1.34) and of severe AP, greater numbers of systemic and local complications, and increased mortality ${ }^{58}$. Central fat distribution has been associated with a systemic inflammatory response in patients with $\mathrm{AP}^{59}$. The excess risk from obesity is related to the volume of visceral adipose tissue and the mechanism of injury is related to the proinflammatory effects of unsaturated fatty acids generated by lipolysis ${ }^{60}$.

Obesity is also a risk factor for several types of cancer, including pancreatic. A metaanalysis of 6391 patients with pancreatic cancer found a relative risk of 1.19 for cancer among obese persons, compared with persons of normal weight ${ }^{61}$. Similarly, a pooled analysis of 14 cohort studies found an increased risk for obese persons, persons who gained weight, and persons with a high waist-to-hip ratio ${ }^{62}$. The available data for obesity are stronger than that for diet, and reinforce the concept that maintaining a healthy body weight can prevent pancreatic cancer.

\section{Diabetes, Drug Exposure, and Blood Type}

\section{Diabetes}

In 3 large retrospective cohorts, type 2 diabetes mellitus increased the risk for AP by 1.5-3 fold, after controlling for demographic and other risk factors ${ }^{63-65}$. Compared with nondiabetics, the risk was particularly high in younger diabetic patients (incidence rate ratio of 5.26 for individuals younger than 45 years and 2.44 for individuals older than 45 years) ${ }^{65}$. The use of anti-diabetic medications was found to reduce the excess risk ${ }^{64}$. Interestingly, following case reports of an association with AP, a recent study evaluating reports to the US Food and Drug Administration found a greater than 6-fold increase in the risk of AP among users of medications for type-2 diabetes such as sitagliptin (a dipeptidyl peptidase-4 inhibitor) and exenatide (a glucagon-like peptide-1 analogue) ${ }^{66}$. The rate of diabetes is also increasing in many developing countries, likely from rapid urbanization and adoption of Western lifestyles. This increase means that there will be more cases of AP, either related to diabetes itself or other risk factors associated with diabetes (gallstones and hypertriglyceridemia).

There is a bi-directional relationship between diabetes and pancreatic cancer. Clinicians are aware that new-onset diabetes can be a symptom of pancreatic cancer, particularly in lowweight, middle-age, or older patients with no family history of this disease. In a study of subjects with new-onset diabetes, the incidence of pancreatic cancer was about 2.2-fold higher than among non-diabetics. However, the absolute risk is low, because only about $0.5 \%$ of newly diagnosed patients with diabetes developed pancreatic cancer during a 6 year follow up ${ }^{67}$. Diabetes develops more frequently among patients with pancreatic cancer than controls for as many as 5 years before a diagnosis of pancreatic cancer ${ }^{68}$. Aggarwal et al. found that $40 \%$ of patients with pancreatic cancer had an antecedent diagnosis of diabetes in the preceding 3 years, compared to $3-5 \%$ of patients with other forms of cancer ${ }^{69}$.

Patients with well-established, longstanding diabetes have an approximate 2-fold increase in risk of pancreatic cancer. The increase appears to apply to patients with adult-onset 
diabetes $^{70,71}$ and probably those with early-onset or type-I diabetes ${ }^{72}$. Additional studies have found that gestational diabetes increases the risk of pancreatic cancer ${ }^{73,74}$. Interestingly, drugs used to manage diabetes can either reduce (metformin) or increase (insulin or insulin secretagogues) the risk of pancreatic cancer ${ }^{75}$. In the study that evaluated the risk of AP with sitagliptin or exenatide, diabetics exposed to these agents had an increased risk of pancreatic cancer compared with patients taking other types of anti-diabetic drugs ${ }^{66}$. Randomized, controlled trials are required to confirm this risk. The global increase in the incidence of diabetes could affect the incidence of pancreatic cancer.

\section{Drug Exposure}

Medication-induced AP is primarily an idiosyncratic reaction. Many medications have been proposed to cause AP, and this list is likely to increase (for a full review, see Ref ${ }^{76}$ ). No medications are known to cause CP. Several types of drugs could increase or decrease the risk of pancreatic cancer. A cohort study of more than 133,000 men and women found no protective effect of cholesterol-lowering drugs against pancreatic cancer ${ }^{77}$.

Although aspirin and non-steroidal anti-inflammatory drugs (NSAIDS) have been associated with a reduced risk of bowel cancer, 2 meta-analyses of American and European studies published before 2006 did not find that these agents protected against pancreatic cancer ${ }^{78,79}$. More recent studies have yielded somewhat different results. Based on information from the UK General Practice Research Database, Bradley et al. found a reduced risk of pancreatic cancer in patients taking NSAIDS for $>5$ years (an odds ratio of 0.70$)^{80}$. More recent studies have shown that aspirin use appears to lower the risk of pancreatic cancer ${ }^{81,82}$. These studies were based on data from case-control or cohort studies. Using data from randomized controlled trials of the effects of aspirin use on heart disease, Rothwell et al. noted a substantially reduced risk of pancreatic cancer (a relative risk of 0.25 ) among subjects exposed to aspirin for $>5$ years ${ }^{83}$. The association was weaker (a relative risk of 0.84 ) in a follow-up study of persons who took aspirin in the US Cancer Prevention Study II Nutrition Cohort ${ }^{84}$.

\section{Blood Type}

For many years, $\mathrm{ABO}$ blood group status has been associated with gastric cancer. However, a genome-wide association study and conventional epidemiological studies found that non$\mathrm{O}$ blood type increases the risk of pancreatic cancer. Compared with blood group O, subjects with blood types $\mathrm{AO}, \mathrm{AA}, \mathrm{BO}$, or $\mathrm{BB}$ had odds ratios for pancreatic cancer ranging from 1.3 to 2.4. Although the mechanism of this association is unclear, about $15 \% 20 \%$ of all pancreatic cancers could be associated with non-O blood type ${ }^{85-87}$. In a large US study, no significant association was detected between blood group and $\mathrm{CP}^{88}$.

\section{Other Risk Factors for Pancreatitis}

\section{Gallstones}

Gallstones are the most common cause of $\mathrm{AP}^{10}$. The prevalence of gallstones in the US adult population is $7 \%{ }^{89}$. The risk of gallstone-related pancreatitis increases with age and is higher in women, consistent with the demographic distribution of gallstones. It is important to perform cholecystectomy as soon as feasible after an attack of gallstone-related AP, to eliminate the risk of future attacks. A delay in cholecystectomy increases the risk of recurrence and subsequent attacks could be more severe than the first. Gallstones do not cause CP. 


\section{Metabolic Factors}

Hypertriglyceridemia is an important but under-recognized cause of acute and recurrent AP. It typically develops in a patient with familial combined hyperlipidemia or familial hypertriglyceridemia who has an additional secondary factor such as uncontrolled diabetes, alcoholism, use of certain medications or during pregnancy. Less frequently, physicians may encounter a patients with familial chylomicronemic syndrome who presents with $\mathrm{AP}^{90}$. Although very high serum levels of triglycerides ( $\geq 1000 \mathrm{mg} / \mathrm{dl}$ ) are associated with pancreatitis, a recent population-based study found that after controlling for demographic factors and lifestyle habits, patients with even modest increases in serum levels of triglycerides had an increased risk of $\mathrm{AP}^{91}$. On further analysis, the risk was specifically increased in patients with AP from non-alcohol, non-obstructive causes-patients with idiopathic pancreatitis. Although uncommon, hypertriglyceridemia can cause $\mathrm{CP}^{92}$.

Other uncommon but established metabolic risk factors include hypercalcemia, renal failure, and acidosis. A population-based study reported that subjects with primary

hyperparathyroidism had a level of risk of pancreatitis similar to controls ${ }^{93}$. Specific genetic variants were identified in patients with primary hyperparathyroidism who also had pancreatitis ${ }^{94,95}$.

\section{Autoimmune Diseases}

Celiac disease increases the risk of pancreatitis by about 3-fold (a hazard ratio of 2.85$)^{96}$. The risks of AP and $\mathrm{CP}$ are also increased among patients with inflammatory bowel disease, systemic lupus erythematosis, and other disorders, although exact estimates are not available. Fewer than 5\% of patients with pancreatitis who undergo evaluation at tertiary centers are diagnosed with autoimmune pancreatitis. Among patients with autoimmune pancreatitis, only $10 \% 25 \%$ have features of $\mathrm{AP}$ or $\mathrm{CP}$ at the time of presentation ${ }^{97}$. Although autoimmune pancreatitis is considered to be a form of $\mathrm{CP}$, it has distinct clinical and histologic features and responds well to steroid therapy. The incidence and prevalence of autoimmune pancreatitis in Japan in 2007 were reported to be $0.9 / 100,000$ persons/year and 2.2/100,000 persons, respectively ${ }^{98}$.

\section{Anatomic Abnormalities and Duct Obstruction}

Although some anatomic abnormalities of the pancreas (annular pancreas and ductal stricture) are accepted causes of AP and recurrent AP, the role of other anatomic (pancreas divisum) or functional abnormalities (sphincter of oddi dysfunction) is controversial. In a recent study of patients with recurrent $\mathrm{AP}$ or $\mathrm{CP}$, the prevalence of pancreas divisum in patients with variants of the cystic fibrosis transmembrane receptor gene (47\%) was significantly higher than patients with idiopathic $(5 \%)$ or alcohol-related $(7 \%)$ pancreatitis, other related genetic factors (variants in PRSS1 or SPINK1] (16\%), or control subjects $(7 \%)^{99}$. The authors concluded that pancreas divisum by itself does not cause pancreatitis but could act as a cofactor with genetic factors. Prolonged ductal obstruction can cause histologic, structural, and functional changes consistent with CP.

\section{Other Risk Factors for Pancreatic Cancer}

\section{Chronic Pancreatitis}

A meta-analysis of 6 cohort studies and 1 case-control study found that the pooled relative risk estimate for pancreatic cancer among patients with CP is $13.3^{100}$. Among individuals with the rare form of pancreatitis found mostly in tropical countries, the association appears to be even stronger ${ }^{101}$. Pancreatic stellate cells link pancreatitis and cancer ${ }^{102}$. One pooled analysis of 5048 patients with pancreatic cancer (in 10 case-control studies) found only a small association between pancreatic cancer and antecedent CP (odds ratio of 2.7) ${ }^{103}$, 
although this might be because the study included some patients without well-documented $\mathrm{CP}$. Nonetheless, given the low incidence of $\mathrm{CP}$ and the low incidence of pancreatic cancer in patients with $\mathrm{CP}(<5 \%), \mathrm{CP}$ is a rare cause of pancreatic cancer.

\section{Hereditary Pancreatitis}

Hereditary pancreatitis is a rare, inherited form of pancreatitis that phenotypically resembles other forms of pancreatitis except for its early age of onset, strong family history, and significant increase in risk for pancreatic cancer. It is an autosomal dominant disease with about $80 \%$ penetrance, and most patients develop symptoms before they are 20 years old. Patients with hereditary pancreatitis have a high risk of developing pancreatic cancer (a pooled relative risk of 69$)^{100}$, with a lifetime risk of $40-55 \%{ }^{104-106}$.

\section{Infectious Diseases}

There have been a few studies of associations between viral infections and pancreatic cancer. Hepatitis B, a strong risk factor for liver cancer, has been reported to also lead to pancreatic cancer ${ }^{107,108}$. However, in a population-based study of US veterans, Hepatitis C was not associated with an increased risk of pancreatic cancer ${ }^{109}$. Helicobacter pylori infection was found to increase risk for pancreatic cancer by a pooled odds ratio of 1.4, based on a meta-analysis of 6 studies published from 1998 through 2010; there was minimal evidence for heterogeneity among studies ${ }^{110}$. Based on these data, we might expect that the geographic distribution of pancreatic cancer would be similar to that of $H$ pylori infection; this is not the case, so further studies of this association are needed.

\section{Disease Progression and Mortality}

There are data to indicate that AP progresses to recurrent $\mathrm{AP}$ and then to $\mathrm{CP}$, in a disease continuum $^{33}, 111-113$. Overall, about $20 \% 30 \%$ of patients with AP have a recurrence and about $10 \%$ develop CP. Progression from AP to CP occurs more frequently with continued exposure to alcohol or smoking and in patients with genetic causes of pancreatitis (hereditary pancreatitis). Patients with pancreatitis should receive appropriate counseling and be referred to rehabilitation services, when appropriate.

AP has an overall low mortality, of approximately $1 \%^{1}$. The risk of death increases with age, co-morbidities, and severe disease; in a recent meta-analysis, the risk of death was the highest among patients with both organ failure and infected necrosis ${ }^{114}$. Proportional mortality has decreased over time, likely from better intensive and supportive care, clarity on optimal timing of interventions for complications (surgery, endoscopic, or percutaneous drainage), and increased detection of milder cases. Although data are limited, the population mortality has not decreased ${ }^{10}$. Patients with CP have shorter survival times than the population ${ }^{7}, 115$, but most die from non-pancreatic causes, such as other chronic diseases, cancers, or infections. Mortality is high among patients with pancreatic cancer. The number of deaths each year from pancreatic cancer is approximately equal to the number of new cases, and the 5-year survival rate is approximately $6 \%{ }^{9}$.

\section{Future Directions}

Much pancreatic disease research has focused on identifying risk factors, clarifying the relationship between risk factors and disease, and discovering better methods for diagnosis, management, and prevention of pancreatitis. Faster, less-costly methods of genetic analysis, which are rapidly becoming available, will provide much-needed answers to the numerous unsolved questions concerning all types of pancreatic disorders. 


\section{Acknowledgments}

Dr. Yadav is supported in part by the National Institutes of Health (NIDDK 077906).

The authors thank Michelle L Kienholz, Department of Medicine, University of Pittsburgh for critical review and editorial assistance.

\section{References}

1. Peery AF, Dellon ES, Lund J, et al. Burden of Gastrointestinal Disease in the United States: 2012 Update. Gastroenterology. 2012; 143:1179-87. [PubMed: 22885331]

2. Yang AL, Vadhavkar S, Singh G, et al. Epidemiology of alcohol-related liver and pancreatic disease in the United States. Arch Intern Med. 2008; 168:649-56. [PubMed: 18362258]

3. Satoh K, Shimosegawa T, Masamune A, et al. Nationwide epidemiological survey of acute pancreatitis in Japan. Pancreas. 2011; 40:503-7. [PubMed: 21499203]

4. Shen HN, Lu CL, Li CY. Epidemiology of first-attack acute pancreatitis in Taiwan from 2000 through 2009: a nationwide population-based study. Pancreas. 2012; 41:696-702. [PubMed: 22699142]

5. Yadav D, Whitcomb DC. The role of alcohol and smoking in pancreatitis. Nat Rev Gastroenterol Hepatol. 2010; 7:131-45. [PubMed: 20125091]

6. Hirota M, Shimosegawa T, Masamune A, et al. The sixth nationwide epidemiological survey of chronic pancreatitis in Japan. Pancreatology. 2012; 12:79-84. [PubMed: 22487515]

7. Yadav D, Timmons L, Benson JT, et al. Incidence, prevalence, and survival of chronic pancreatitis: a population-based study. Am J Gastroenterol. 2011; 106:2192-9. [PubMed: 21946280]

8. Frey CF, Zhou H, Harvey DJ, et al. The incidence and case-fatality rates of acute biliary, alcoholic, and idiopathic pancreatitis in California, 1994-2001. Pancreas. 2006; 33:336-44. [PubMed: 17079936]

9. National Cancer Institute. [Accessed August 26,2012] http://seercancergov/statfacts/html/ pancreashtml

10. Yadav D, Lowenfels AB. Trends in the epidemiology of the first attack of acute pancreatitis: a systematic review. Pancreas. 2006; 33:323-30. [PubMed: 17079934]

11. Mohan V, Farooq S, Deepa M. Prevalence of fibrocalculous pancreatic diabetes in Chennai in South India. JOP. 2008; 9:489-92. [PubMed: 18648140]

12. Balaji LN, Tandon RK, Tandon BN, et al. Prevalence and clinical features of chronic pancreatitis in southern India. Int J Pancreatol. 1994; 15:29-34. [PubMed: 8195640]

13. Saligram S, Lo D, Saul M, et al. Analyses of hospital administrative data that use diagnosis codes overestimate the cases of acute pancreatitis. Clin Gastroenterol Hepatol. 2012; 10:805-811. e1. [PubMed: 22504004]

14. Yadav D, Ng B, Saul M, et al. Relationship of serum pancreatic enzyme testing trends with the diagnosis of acute pancreatitis. Pancreas. 2011; 40:383-9. [PubMed: 21283039]

15. [Accessed September 11, 2012] Global Status Report on Alcohol and Health. 2011. http:// www.who.int/substance_abuse/publications/global_alcohol_report/en/index.html

16. Raimondi S, Maisonneuve P, Lowenfels AB. Epidemiology of pancreatic cancer: an overview. Nat Rev Gastroenterol Hepatol. 2009; 6:699-708. [PubMed: 19806144]

17. [Accessed August 28, 2012] World Wide cancer statistics. www.wcrf.org/cancer_statistics/ world_cancerstatistics.php

18. Lankisch PG, Lowenfels AB, Maisonneuve P. What is the risk of alcoholic pancreatitis in heavy drinkers? Pancreas. 2002; 25:411-2. [PubMed: 12409838]

19. Garg PK. Chronic pancreatitis in India and Asia. Curr Gastroenterol Rep. 2012; 14:118-24. [PubMed: 22327961]

20. Morinville VD, Barmada MM, Lowe ME. Increasing Incidence of Acute Pancreatitis at an American Pediatric Tertiary Care Center: Is Greater Awareness Among Physicians Responsible? Pancreas. 2009; 39:5-8. [PubMed: 19752770] 
21. Bai HX, Lowe ME, Husain SZ. What have we learned about acute pancreatitis in children? J Pediatr Gastroenterol Nutr. 2011; 52:262-70. [PubMed: 21336157]

22. Lucidi V, Alghisi F, Dall'Oglio L, et al. The etiology of acute recurrent pancreatitis in children: a challenge for pediatricians. Pancreas. 2011; 40:517-21. [PubMed: 21499205]

23. Sultan M, Werlin S, Venkatasubramani N. Genetic prevalence and characteristics in children with recurrent pancreatitis. J Pediatr Gastroenterol Nutr. 2012; 54:645-50. [PubMed: 22094894]

24. Yadav D, Muddana V, O'Connell M. Hospitalizations for chronic pancreatitis in allegheny county, pennsylvania, USA. Pancreatology. 2011; 11:546-52. [PubMed: 22205468]

25. National Center for Health Statistics. Health US, 2011: With Special Feature on Socioeconomic Status and Health. Hyattsville, MD: 2012. [Accessed September 13, 2012]

26. Pandol SJ, Lugea A, Mareninova OA, et al. Investigating the pathobiology of alcoholic pancreatitis. Alcohol Clin Exp Res. 35:830-7. [PubMed: 21284675]

27. Yadav D, Eigenbrodt ML, Briggs MJ, et al. Pancreatitis: prevalence and risk factors among male veterans in a detoxification program. Pancreas. 2007; 34:390-8. [PubMed: 17446836]

28. Kristiansen L, Gronbaek M, Becker U, et al. Risk of pancreatitis according to alcohol drinking habits: a population-based cohort study. Am J Epidemiol. 2008; 168:932-7. [PubMed: 18779386]

29. Cote GA, Yadav D, Slivka A, et al. Alcohol and smoking as risk factors in an epidemiology study of patients with chronic pancreatitis. Clin Gastroenterol Hepatol. 2011; 9:266-73. quiz e27. [PubMed: 21029787]

30. Frulloni L, Gabbrielli A, Pezzilli R, et al. Chronic pancreatitis: report from a multicenter Italian survey (PanCroInfAISP) on 893 patients. Dig Liver Dis. 2009; 41:311-7. [PubMed: 19097829]

31. Yadav D, Hawes RH, Brand RE, et al. Alcohol consumption, cigarette smoking, and the risk of recurrent acute and chronic pancreatitis. Arch Intern Med. 2009; 169:1035-45. [PubMed: 19506173]

32. Irving HM, Samokhvalov AV, Rehm J. Alcohol as a risk factor for pancreatitis. A systematic review and meta-analysis. JOP. 2009; 10:387-92. [PubMed: 19581740]

33. Takeyama Y. Long-term prognosis of acute pancreatitis in Japan. Clin Gastroenterol Hepatol. 2009; 7:S15-7. [PubMed: 19896091]

34. Nordback I, Pelli H, Lappalainen-Lehto R, et al. The recurrence of acute alcohol-associated pancreatitis can be reduced: a randomized controlled trial. Gastroenterology. 2009; 136:848-55. [PubMed: 19162029]

35. Sadr Azodi O, Orsini N, Andren-Sandberg A, et al. Effect of type of alcoholic beverage in causing acute pancreatitis. Br J Surg. 2011; 98:1609-16. [PubMed: 21811997]

36. Phillip V, Huber W, Hagemes F, et al. Incidence of acute pancreatitis does not increase during Oktoberfest, but is higher than previously described in Germany. Clin Gastroenterol Hepatol. 2011; 9:995-1000. e3. [PubMed: 21723238]

37. Nordback I, Pelli H, Lappalainen-Lehto R, et al. Is it long-term continuous drinking or the postdrinking withdrawal period that triggers the first acute alcoholic pancreatitis? Scand $\mathrm{J}$ Gastroenterol. 2005; 40:1235-9. [PubMed: 16265780]

38. Gapstur SM, Jacobs EJ, Deka A, et al. Association of alcohol intake with pancreatic cancer mortality in never smokers. Arch Intern Med. 2011; 171:444-51. [PubMed: 21403041]

39. Lucenteforte E, La Vecchia C, Silverman D, et al. Alcohol consumption and pancreatic cancer: a pooled analysis in the International Pancreatic Cancer Case-Control Consortium (PanC4). Ann Oncology. 2012; 23:374-82.

40. Yen S, Hsieh CC, MacMahon B. Consumption of alcohol and tobacco and other risk factors for pancreatitis. Am J Epidemiol. 1982; 116:407-414. [PubMed: 7124709]

41. Andriulli A, Botteri E, Almasio PL, et al. Smoking as a cofactor for causation of chronic pancreatitis: a meta-analysis. Pancreas. 2010; 39:1205-10. [PubMed: 20622705]

42. Lindkvist B, Appelros S, Manjer J, et al. A prospective cohort study of smoking in acute pancreatitis. Pancreatology. 2008; 8:63-70. [PubMed: 18235217]

43. Sadr-Azodi O, Andren-Sandberg A, Orsini N, et al. Cigarette smoking, smoking cessation and acute pancreatitis: a prospective population-based study. Gut. 2012; 61:262-7. [PubMed: 21836026] 
44. Tolstrup JS, Kristiansen L, Becker U, et al. Smoking and risk of acute and chronic pancreatitis among women and men: a population-based cohort study. Arch Intern Med. 2009; 169:603-9. [PubMed: 19307524]

45. Talamini G, Bassi C, Falconi M, et al. Smoking cessation at the clinical onset of chronic pancreatitis and risk of pancreatic calcifications. Pancreas. 2007; 35:320-6. [PubMed: 18090237]

46. Yadav D, Slivka A, Sherman S, et al. Smoking is underrecognized as a risk factor for chronic pancreatitis. Pancreatology. 2010; 10:713-9. [PubMed: 21242712]

47. Bosetti C, Lucenteforte E, Silverman DT, et al. Cigarette smoking and pancreatic cancer: an analysis from the International Pancreatic Cancer Case-Control Consortium (Panc4). Ann Oncology. 2012; 23:1880-8.

48. Chuang SC, Gallo V, Michaud D, et al. Exposure to environmental tobacco smoke in childhood and incidence of cancer in adulthood in never smokers in the European Prospective Investigation into Cancer and Nutrition. Cancer Causes Control. 2011; 22:487-94. [PubMed: 21279734]

49. Vrieling A, Bueno-de-Mesquita HB, Boshuizen HC, et al. Cigarette smoking, environmental tobacco smoke exposure and pancreatic cancer risk in the European Prospective Investigation into Cancer and Nutrition. Int J Cancer. 2010; 126:2394-403. [PubMed: 19790196]

50. Jang JH, Cotterchio M, Borgida A, et al. Genetic variants in carcinogen-metabolizing enzymes, cigarette smoking and pancreatic cancer risk. Carcinogenesis. 2012; 33:1430.

51. Pandol SJ, Apte MV, Wilson JS, et al. The burning question: Why is smoking a risk factor for pancreatic cancer? Pancreatology. 2012; 12:344-9. [PubMed: 22898636]

52. Jiao L, Mitrou PN, Reedy J, et al. A combined healthy lifestyle score and risk of pancreatic cancer in a large cohort study. Arch Intern Med. 2009; 169:764-70. [PubMed: 19398688]

53. Stolzenberg-Solomon RZ, Cross AJ, Silverman DT, et al. Meat and meat-mutagen intake and pancreatic cancer risk in the NIH-AARP cohort. Cancer Epidemiol Biomarkers Prev. 2007; 16:2664-75. [PubMed: 18086772]

54. Vrieling A, Verhage BA, van Duijnhoven FJ, et al. Fruit and vegetable consumption and pancreatic cancer risk in the European Prospective Investigation into Cancer and Nutrition. Int J Cancer. 2009; 124:1926-34. [PubMed: 19107929]

55. Jiao L, Flood A, Subar AF, et al. Glycemic index, carbohydrates, glycemic load, and the risk of pancreatic cancer in a prospective cohort study. Cancer Epidemiology Biomarkers Prev. 2009; 18:1144-51.

56. Shanahan F. The colonic microbiota in health and disease. Curr Op Gastroenterol. 2013; 29:49-54.

57. Sadr-Azodi O, Orsini N, Andren-Sandberg A, et al. Abdominal and Total Adiposity and The Risk of Acute Pancreatitis: A Population-Based Prospective Cohort Study. Am J Gastroenterol. 2013; 108:133-9. [PubMed: 23147519]

58. Hong S, Qiwen B, Ying J, et al. Body mass index and the risk and prognosis of acute pancreatitis: a meta-analysis. Eur J Gastroenterol Hepatol. 2011; 23:1136-43. [PubMed: 21904207]

59. Sempere L, Martinez J, de Madaria E, et al. Obesity and fat distribution imply a greater systemic inflammatory response and a worse prognosis in acute pancreatitis. Pancreatology. 2008; 8:25764. [PubMed: 18497538]

60. Navina S, Acharya C, DeLany JP, et al. Lipotoxicity causes multisystem organ failure and exacerbates acute pancreatitis in obesity. Sci transl Med. 2011; 3:107ra110.

61. Berrington de Gonzalez A, Sweetland S, Spencer E. A meta-analysis of obesity and the risk of pancreatic cancer. Br J Cancer. 2003; 89:519-23. [PubMed: 12888824]

62. Genkinger JM, Spiegelman D, Anderson KE, et al. A pooled analysis of 14 cohort studies of anthropometric factors and pancreatic cancer risk. Int J Cancer. 2011; 129:1708-17. [PubMed: 21105029]

63. Girman CJ, Kou TD, Cai B, et al. Patients with type 2 diabetes mellitus have higher risk for acute pancreatitis compared with those without diabetes. Diabetes Obes Metabol. 2010; 12:766-71.

64. Lai SW, Muo CH, Liao KF, et al. Risk of acute pancreatitis in type 2 diabetes and risk reduction on anti-diabetic drugs: a population-based cohort study in Taiwan. Am J Gastroenterol. 2011; 106:1697-704. [PubMed: 21577242] 
65. Noel RA, Braun DK, Patterson RE, et al. Increased risk of acute pancreatitis and biliary disease observed in patients with type 2 diabetes: a retrospective cohort study. Diabetes care. 2009; 32:834-8. [PubMed: 19208917]

66. Elashoff M, Matveyenko AV, Gier B, et al. Pancreatitis, pancreatic, and thyroid cancer with glucagon-like peptide-1-based therapies. Gastroenterology. 2011; 141:150-6. [PubMed: 21334333]

67. Gupta S, Vittinghoff E, Bertenthal D, et al. New-onset diabetes and pancreatic cancer. Clin Gastroenterol Hepatol. 2006; 4:1366-72. quiz 1301. [PubMed: 16945591]

68. Chari ST, Leibson CL, Rabe KG, et al. Probability of pancreatic cancer following diabetes: a population-based study. Gastroenterology. 2005; 129:504-11. [PubMed: 16083707]

69. Aggarwal G, Kamada P, Chari ST. Prevalence of Diabetes Mellitus in Pancreatic Cancer Compared to Common Cancers. Pancreas. 2012 Epub ahead of print.

70. Ben Q, Xu M, Ning X, et al. Diabetes mellitus and risk of pancreatic cancer: A meta-analysis of cohort studies. Eur J Cancer. 2011; 47:1928-37. [PubMed: 21458985]

71. Li D, Tang H, Hassan MM, et al. Diabetes and risk of pancreatic cancer: a pooled analysis of three large case-control studies. Cancer Causes Control. 2011; 22:189-97. [PubMed: 21104117]

72. Stevens RJ, Roddam AW, Beral V. Pancreatic cancer in type 1 and young-onset diabetes: systematic review and meta-analysis. Br J Cancer. 2007; 96:507-9. [PubMed: 17224924]

73. Perrin MC, Terry MB, Kleinhaus K, et al. Gestational diabetes as a risk factor for pancreatic cancer: a prospective cohort study. BMC medicine. 2007; 5:25. [PubMed: 17705823]

74. Sella T, Chodick G, Barchana M, et al. Gestational diabetes and risk of incident primary cancer: a large historical cohort study in Israel. Cancer Causes Control. 2011; 22:1513-20. [PubMed: 21847538]

75. Li D, Yeung SC, Hassan MM, et al. Antidiabetic therapies affect risk of pancreatic cancer. Gastroenterology. 2009; 137:482-8. [PubMed: 19375425]

76. Badalov N, Baradarian R, Iswara K, et al. Drug-induced acute pancreatitis: an evidence- based review. Clin Gastroenterol Hepatol. 2007; 5:648-61. quiz 644. [PubMed: 17395548]

77. Jacobs EJ, Newton CC, Thun MJ, et al. Long-term use of cholesterol-lowering drugs and cancer incidence in a large United States cohort. Cancer Res. 2011; 71:1763-71. [PubMed: 21343395]

78. Capurso G, Schunemann HJ, Terrenato I, et al. Meta-analysis: the use of non-steroidal antiinflammatory drugs and pancreatic cancer risk for different exposure categories. Alim Pharmacol Ther. 2007; 26:1089-99.

79. Larsson SC, Giovannucci E, Bergkvist L, et al. Aspirin and nonsteroidal anti-inflammatory drug use and risk of pancreatic cancer: a meta-analysis. Cancer Epidemiol Biomarkers Prev. 2006; 15:2561-4. [PubMed: 17164387]

80. Bradley MC, Hughes CM, Cantwell MM, et al. Non-steroidal anti-inflammatory drugs and pancreatic cancer risk: a nested case-control study. Br J Cancer. 2010; 102:1415-21. [PubMed: 20372155]

81. Bonifazi M, Gallus S, Bosetti C, et al. Aspirin use and pancreatic cancer risk. Eur J Cancer Prev. 2010; 19:352-4. [PubMed: 20502343]

82. Tan XL, Reid Lombardo KM, Bamlet WR, et al. Aspirin, nonsteroidal anti-inflammatory drugs, acetaminophen, and pancreatic cancer risk: a clinic-based case-control study. Cancer Prev Res. 2011; 4:1835-41.

83. Rothwell PM, Fowkes FG, Belch JF, et al. Effect of daily aspirin on long-term risk of death due to cancer: analysis of individual patient data from randomised trials. Lancet. 2011; 377:31-41. [PubMed: 21144578]

84. Jacobs EJ, Newton CC, Gapstur SM, et al. Daily Aspirin Use and Cancer Mortality in a Large US Cohort. J Natl Cancer Inst. 2012; 104:1208-17. [PubMed: 22888140]

85. Amundadottir L, Kraft P, Stolzenberg-Solomon RZ, et al. Genome-wide association study identifies variants in the $\mathrm{ABO}$ locus associated with susceptibility to pancreatic cancer. Nat Genetics. 2009; 41:986-90. [PubMed: 19648918]

86. Wolpin BM, Chan AT, Hartge P, et al. ABO blood group and the risk of pancreatic cancer. J Natl Cancer Inst. 2009; 101:424-31. [PubMed: 19276450] 
87. Wolpin BM, Kraft P, Gross M, et al. Pancreatic cancer risk and ABO blood group alleles: results from the pancreatic cancer cohort consortium. Cancer Res. 2010; 70:1015-23. [PubMed: 20103627]

88. Greer JB, LaRusch J, Brand RE, et al. ABO blood group and chronic pancreatitis risk in the NAPS2 cohort. Pancreas. 40:1188-94. [PubMed: 21792085]

89. Ruhl CE, Everhart JE. Gallstone disease is associated with increased mortality in the United States. Gastroenterology. 2011; 140:508-16. [PubMed: 21075109]

90. Yadav D, Pitchumoni CS. Issues in hyperlipidemic pancreatitis. J Clin Gastroenterol. 2003; 36:5462. [PubMed: 12488710]

91. Lindkvist B, Appelros S, Regner S, et al. A prospective cohort study on risk of acute pancreatitis related to serum triglycerides, cholesterol and fasting glucose. Pancreatology. 2012; 12:317-24. [PubMed: 22898632]

92. Truninger K, Schmid PA, Hoffmann MM, et al. Recurrent acute and chronic pancreatitis in two brothers with familial chylomicronemia syndrome. Pancreas. 2006; 32:215-9. [PubMed: 16552344]

93. Khoo TK, Vege SS, Abu-Lebdeh HS, et al. Acute pancreatitis in primary hyperparathyroidism: a population-based study. J Clin Endocrinol Metabol. 2009; 94:2115-8.

94. Felderbauer P, Karakas E, Fendrich V, et al. Pancreatitis risk in primary hyperparathyroidism: relation to mutations in the SPINK1 trypsin inhibitor (N34S) and the cystic fibrosis gene. Am J Gastroenterol. 2008; 103:368-74. [PubMed: 18076731]

95. Felderbauer P, Karakas E, Fendrich V, et al. Multifactorial genesis of pancreatitis in primary hyperparathyroidism: evidence for "protective" (PRSS2) and "destructive" (CTRC) genetic factors. Exp Clin Endocrinol Diabetes. 2011; 119:26-9. [PubMed: 20625975]

96. Sadr-Azodi O, Sanders DS, Murray JA, et al. Patients With Celiac Disease Have an Increased Risk for Pancreatitis. Clin Gastroenterol Hepatol. 2012; 10:1136-42. e3. [PubMed: 22801059]

97. Sah RP, Pannala R, Chari ST, et al. Prevalence, diagnosis, and profile of autoimmune pancreatitis presenting with features of acute or chronic pancreatitis. Clin Gastroenterol Hepatol. 2010; 8:91-6. [PubMed: 19800984]

98. Kanno A, Nishimori I, Masamune A, et al. Nationwide epidemiological survey of autoimmune pancreatitis in Japan. Pancreas. 2012; 41:835-9. [PubMed: 22466167]

99. Bertin C, Pelletier AL, Vullierme MP, et al. Pancreas divisum is not a cause of pancreatitis by itself but acts as a partner of genetic mutations. Am J Gastroenterol. 2012; 107:311-7. [PubMed: 22158025]

100. Raimondi S, Lowenfels AB, Morselli-Labate AM, et al. Pancreatic cancer in chronic pancreatitis; aetiology, incidence, and early detection. Best Practice Res Clin Gastroenterol. 2010; 24:349-58.

101. Chari ST, Mohan V, Pitchumoni CS, et al. Risk of pancreatic carcinoma in tropical calcifying pancreatitis: an epidemiologic study. Pancreas. 1994; 9:62-6. [PubMed: 8108373]

102. Algul H, Treiber M, Lesina M, et al. Mechanisms of disease: chronic inflammation and cancer in the pancreas--a potential role for pancreatic stellate cells? Nat Clin Practice Gastroenterol Hepatol. 2007; 4:454-62.

103. Duell EJ, Lucenteforte E, Olson SH, et al. Pancreatitis and pancreatic cancer risk: a pooled analysis in the International Pancreatic Cancer Case-Control Consortium (PanC4). Ann Oncology. 2012; 23:2964-70.

104. Howes N, Lerch MM, Greenhalf W, et al. Clinical and genetic characteristics of hereditary pancreatitis in Europe. Clin Gastroenterol Hepatol. 2004; 2:252-61. [PubMed: 15017610]

105. Lowenfels AB, Maisonneuve P, DiMagno EP, et al. Hereditary pancreatitis and the risk of pancreatic cancer. International Hereditary Pancreatitis Study Group. J Natl Cancer Inst. 1997; 89:442-6. [PubMed: 9091646]

106. Rebours V, Boutron-Ruault MC, Schnee M, et al. Risk of pancreatic adenocarcinoma in patients with hereditary pancreatitis: a national exhaustive series. Am J Gastroenterol. 2008; 103:111-9. [PubMed: 18184119]

107. Ben Q, Li Z, Liu C, et al. Hepatitis B virus status and risk of pancreatic ductal adenocarcinoma: a case-control study from China. Pancreas. 2012; 41:435-40. [PubMed: 22422136] 
108. Hassan MM, Li D, El-Deeb AS, et al. Association between hepatitis B virus and pancreatic cancer. J Clin Oncol. 2008; 26:4557-62. [PubMed: 18824707]

109. El-Serag HB, Engels EA, Landgren O, et al. Risk of hepatobiliary and pancreatic cancers after hepatitis C virus infection: A population-based study of U.S. veterans. Hepatology. 2009; 49:116-23. [PubMed: 19085911]

110. Trikudanathan G, Philip A, Dasanu CA, et al. Association between Helicobacter pylori infection and pancreatic cancer. A cumulative meta-analysis. JOP. 2011; 12:26-31. [PubMed: 21206097]

111. Lankisch PG, Breuer N, Bruns A, et al. Natural history of acute pancreatitis: a long-term population-based study. Am J Gastroenterol. 2009; 104:2797-805. quiz 2806. [PubMed: 19603011]

112. Nojgaard C, Becker U, Matzen P, et al. Progression from acute to chronic pancreatitis: prognostic factors, mortality, and natural course. Pancreas. 2011; 40:1195-200. [PubMed: 21926938]

113. Yadav D, O'Connell M, Papachristou GI. Natural history following the first attack of acute pancreatitis. Am J Gastroenterol. 2012; 107:1096-103. [PubMed: 22613906]

114. Petrov MS, Shanbhag S, Chakraborty M, et al. Organ failure and infection of pancreatic necrosis as determinants of mortality in patients with acute pancreatitis. Gastroenterology. 2010; 139:813-20. [PubMed: 20540942]

115. Nojgaard C, Bendtsen F, Becker U, et al. Danish patients with chronic pancreatitis have a fourfold higher mortality rate than the Danish population. Clin Gastroenterol Hepatol. 2010; 8:38490. [PubMed: 20036762]

\section{Biographies}
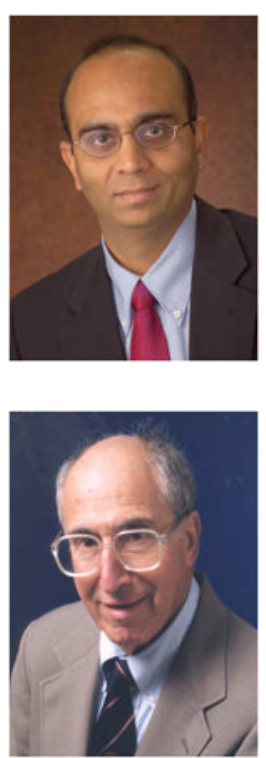


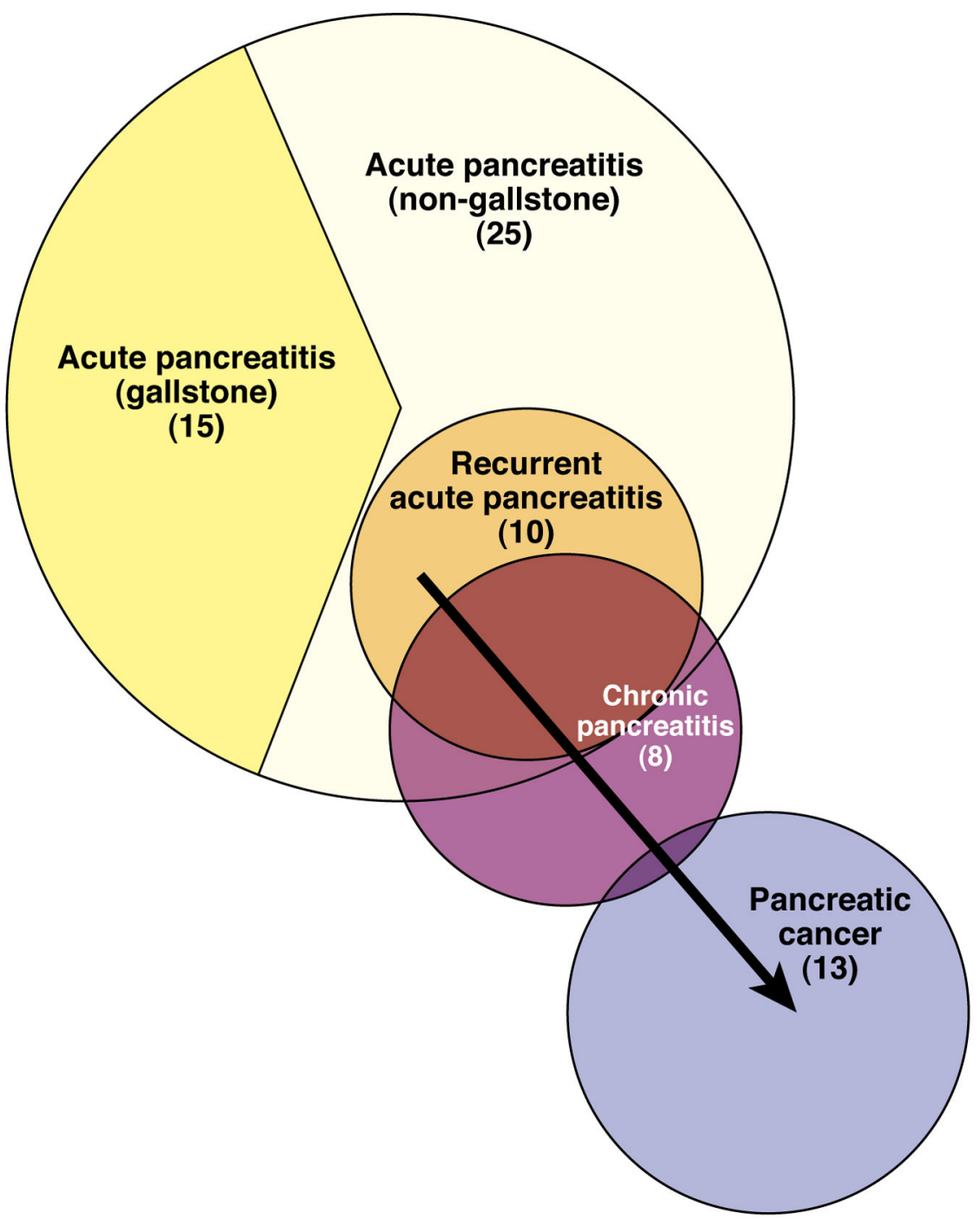

Figure 1. Incidence Rates for Pancreatitis and Pancreatic Cancer in the US Numbers in parenthesis indicate approximate yearly incident rates per 100,000 persons. Arrow indicates relationship between benign and malignant disease. Recurrent AP develops predominately in patients with non-gallstone related pancreatitis, although it can develop in patients with gallstone-related pancreatitis when cholecystectomy has been delayed or refused.

Ref. 8,9,24 


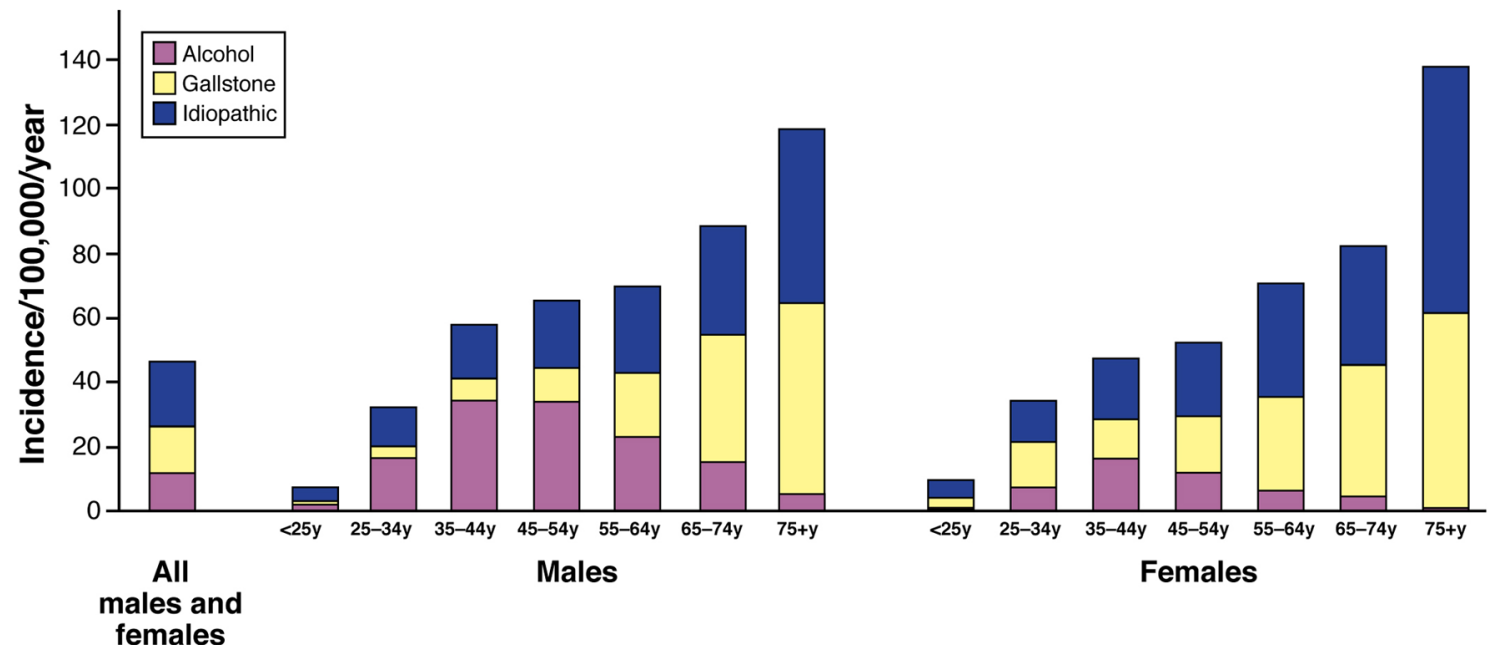

females

Figure 2. Incidence of AP

Graph shows incidence from 1996-2005 in White and Black residents of Allegheny County, PA, US, based on age-group, sex and etiology.

Source: Allegheny County census data (http://www.cdc.gov/nchs/nvss.htm); pancreatitis data (Ref. 113). Incidence data is shown only for patients with alcohol, gallstone or idiopathic etiology. Rate for all patients is age, sex and race adjusted to 2000 US population. 


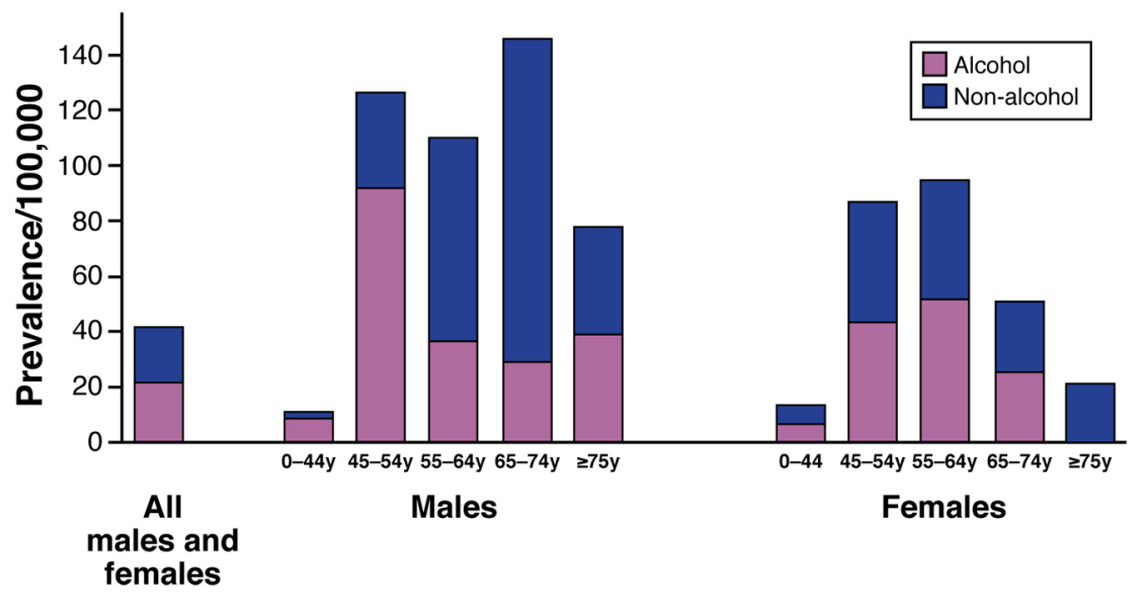

Figure 3. Prevalence of $\mathbf{C P}$

Graph shows prevalence of CP in 2006, in Olmsted County, MN, US, based on age-group, sex and etiology.

Data in part from Ref. 7 (with permission). Rate for all patients is age and sex adjusted to 2000 US White population. 


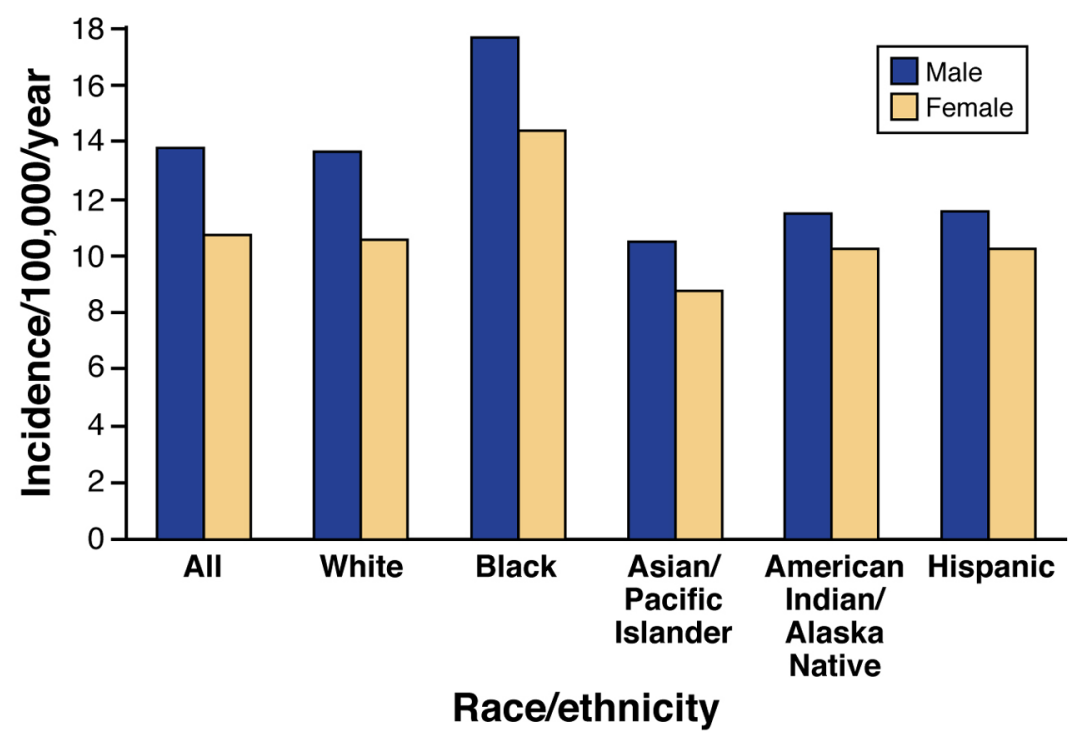

Figure 4. Incidence of Pancreatic Cancer Incidence of pancreatic cancer from 2005 to 2009 in the US, based on sex and racial groups. Ref. 9 